\title{
Editorial special issue: the soil, the seed, the microbes and the plant
}

\author{
Eric B. Nelson • Philippe Simoneau • Matthieu Barret • \\ Birgit Mitter • Stéphane Compant $\mathbb{D}$
}

Received: 16 October 2017 / Accepted: 16 January 2018 /Published online: 23 January 2018

(C) Springer International Publishing AG, part of Springer Nature 2018

\section{Introduction}

Despite the long-held belief that reproductive and disseminative organs of plants are sterile, it is now well established that seeds host diverse microbial assemblages (Hardoim et al. 2015; Truyens et al. 2015). Some of these associated microorganisms contribute to plant health, plant growth, and seed survival while others are detrimental (Barret et al. 2016; Saikkonen et al. 2016). Seeds can facilitate the dispersal of microorganisms, providing for early colonization of a new plant generation. Although seeds are an important means of supporting microbial growth and dispersal, relatively little is known about the ecology of seed-associated microorganisms (Saikkonen et al. 1998; Compant et al. 2010; Truyens et al. 2015; Brader et al. 2017) in comparison with root- and leaf-associated microorganisms

Responsible Editor: Hans Lambers.

\section{E. B. Nelson}

Section of Plant Pathology \& Plant-Microbe Biology, School of Integrative Plant Science, Cornell University, Ithaca, NY 14886, USA

P. Simoneau · M. Barret

IRHS, INRA, AGROCAMPUS-Ouest, Université d'Angers, SFR4207 QUASAV, 42, rue Georges Morel, 49071 Beaucouzé, France

B. Mitter $\cdot$ S. Compant $(\bowtie)$

AIT Austrian Institute of Technology GmbH, Center for Health \& Bioresources, Bioresources Unit, Konrad-Lorenz Straße 24,

3430 Tulln, Austria

e-mail: stephane.compant@ait.ac.at
(Mercado-Blanco and Lugtenberg 2014; MercadoBlanco 2015; Vacher et al. 2016; Compant et al. 2016). In many instances, the composition and structure of the seed microbiota of various plants species have yet to be characterized. This includes the microorganisms living on the surface as well as the inner tissues of the seeds. Furthermore, a thorough understanding of the specific routes of seed transmission of microorganisms needs to be developed. Whereas seed transmission has been thought to occur through three main routes: the internal, floral and external pathways (Maude 1996), the relative importance of these pathways in determining the composition of the seed microbiota remains to be explored. Moreover, the impact of vertical (derived from the mother plant) and horizontal transmission (derived from air-borne or soil-borne microorganisms) in the assembly of seed microbial communities is unclear for some taxa.

As much needs to be understood about seedassociated microbes, perhaps among the most important are resolving the relative roles of horizontal and vertical transmission in establishing the seed microbiota, which could lead to a better understanding of the plant holobiont, its microbiome and functioning, and the potential use of seed-associated microbes for improving agricultural productivity. This understanding could like lead to insights into the evolution of specific microbial taxa within seeds and the relative contributions of various selective forces in shaping the seed microbiota. The unraveling of these processes could provide important knowledge about how beneficial, commensal, and pathogenic fungal and bacterial microorganisms establish 
and maintain intimate associations with their seeds and contribute to the health of the next plant generation, improving our abilities to develop successful application strategies for microbial inoculants and their integration into sustainable crop production and protection.

Since the nineteenth century, advances have been made in our understanding of plant-associated microorganisms. However, for seeds and their microbiota, there remain large gaps in our knowledge. Seed transmission of some microorganisms like Epichloids in grasses (Kauppinen et al. 2016; Saikkonen et al. 2016) or phytopathogenic fungi and bacteria (Li et al. 2017; Brader et al. 2017) have been relatively well studied. However, seed transmission of many plant-associated microorganisms remains unknown.

The contributions in this Special Issue have served to greatly improve our understanding of the mechanisms of seed-microbe-soil interactions, the nature of the microbiota and functioning of the microbiome present within various seeds, the evolution of the seed microbiota, and the routes of microbial colonization. The studies include different beneficial and detrimental microorganisms as fungi and bacteria thriving as endophytes in different kinds of plants. They further describe ways in which specific native or non-native seed microorganisms may be utilized for improving seed and seedling survival and plant health and productivity.

\section{The seed microbiota}

In a Marschner review, Nelson (2018) explores and discusses the complex microbial associations, richness, and dynamics of the seed microbiota, through various stages of the plant's life cycle and the impact on plant health and productivity. Different seeds can vary in the composition of their microbiota, which may be determined by the seed genotypes as well as environmental conditions in which seeds and seedlings develop. Interestingly, Adam et al. (2018) also explore the seed microbiota of different lines of Cucurbita pepo L. where, despite the dominance of members of the Enterobacteriaceae among the different taxa within the seeds, they demonstrate a strong seed genotypespecific microbiota in comparison to rhizosphere bacteria. Sánchez-López et al. (2018) further analyse the core microbiota within seeds of Crotalaria pumila growing in metal mine residues across several seed generations. By analysing the community structure and diversity of endophytic bacteria within seeds, they provide strong evidence that the seed assemblages are similar across generations. However, Rezki et al. (2018), using Raphanus sativus, show that across three generations, seed bacterial and fungal microbial communities display a low heritability, suggesting that ecological drift is an important driver of the structure of the seed bacterial communities but dispersal is involved in the assembly of seed fungal communities. Alibrandi et al. (2018) characterize the seed endophytes of Anadenathera colubrina (Vell.) Brenan by culture-dependent and independent approaches describing specific microbial taxa related to Friedmaniella, Bifidobacterium, Delftia, Anaerococcus and Actinomyces that are associated to this leguminous tree from South America.

\section{The routes and niches of colonization of seed inhabitants}

In studying microbial assemblages within seeds of different plant species, it is important to understand where microorganisms are located and from where they originate. Glassner et al. (2018) analyzed the seeds of Cucumis melo L. by scanning electron microscopy and fluorescence in situ hybridization coupled with confocal microscopy and highlighted not only the different bacterial taxa belonging to the Alpha-, Beta-, Gamma-proteobacteria, Firmicutes and Actinomycetes that inhabit seed tissues, but also their location on and in the seed coat, root-hypocotyl embryo, cotyledons, and the perisperm/endosperm envelope surrounding the embryo. Also using fluorescence in situ hybridization microscopy, Alibrandi et al. (2018) detected Alphaproteobacteria, Firmicutes, and other bacteria in the intercellular spaces of the seed parenchyma and the xylem vessels of Anadenathera colubrina.

Pathogens are of particular interest and can also be seed-borne. An improved knowledge of their niches and routes of colonization is also important in understanding the seed microbiota. Darrasse et al. (2018) demonstrate in this Special Issue the differential niches and routes of transmission of Xanthomonas citri pv. fuscans and nonpathogenic Xanthomonas strains to bean seeds. While Xanthomonas citri is seed-transmitted by the floral pathway, nonpathogenic Xanthomonas strains are not, suggesting different niches and routes of seed colonization. In a commentary by Escobar Rodríguez et al. (2018), authors further discuss the colonization routes and 
describe the sources of seed endophytes such as the anthosphere, carposphere, or pollen and cones in the case of gymnosperms or inner tissues from the soil to reproductive organs and how this might influence the seed microbiota. While we now have a better understanding of how the seed microbiota might be derived, we still lack important knowledge about the specific activities of endophytic microorganisms within the seeds.

\section{Seed- and seedling-microorganism interaction mechanisms}

Within this Special Issue, Pitzschke (2018) demonstrate using germinating quinoa seeds that seed endophytes have the potential to drive plant cell expansion, to move across cell walls, to generate damage-associated molecular patterns (DAMPS) and activate MAPKs in the seeds. Pitzschke further indicates that these endophytic bacteria may facilitate rapid seed germination and confer a primed state directly upon seed rehydration. Seed protection can be, however, dependent on the physiological stage of the seeds. As Chen et al. (2018) point out, dormancy may protect seeds from infection by the pathogen Fusarium tricinctum as nondormant seeds are more susceptible as compared to dormant seeds. However, seedlings can induce defense responses to reduce pathogen infection as Zhang et al. (2018) show through proteome analyses with seedlings of watermelon with activated defense reactions to Fusarium oxysporum.

\section{Native seed endophytes can increase plant growth and health}

Some seed inhabitants are capable of increasing seed germination and seedling growth. Shearin et al. (2018) and White et al. (2018) demonstrate that fungal endophytes such as Phoma, Penicillium, Alternaria as well as various pseudomonads contribute to increased seed germination and growth of invasive Phragmites australis (Cav.) Trin. ex Steud, demonstrating that plant invasions may be facilitated by native seed-borne microorganisms. Whereas we still do not know if seeds recruit specific microorganisms to facilitate the establishment of the next plant generation of plants, it is clear that some endophytes may increase plant growth and protect plants against damping off disease, thus reducing the growth rate of competitive plants such as dandelion and curly dock. These plants may select specific endophytes that contribute to within-field dispersal and decreased biodiversity thus promoting invasive growth.

Not only do seed endophytes contribute to seedling health, but some seeds once germinated can recruit specific microbes to protect the seed from infection. Indeed, rapid seedling growth following germination can be promoted by the recruitment of helper strains. Jack and Nelson (2018) demonstrate this by showing that some microorganisms, which are recruited to the spermosphere (once the seed has germinated), modify seed exudates to reduce zoospore chemotaxis and seed colonization by Pythium aphanidermatum through the production of zoosporolytic compounds.

\section{Use of seed endophytes or other endophytes on seeds and seedlings to increase plant growth and health on non-native hosts}

Seed endophytes are beneficial for the plants from which they were derived, but also to other plants. As a global strategy to reduce chemical fertilizers and pesticides, some endophytes and other members of the phytosphere can be used for plant growth promotion and health. In this Special Issue, Verma et al. (2018) demonstrate that some seed endophytes of the monocotyledonous plant Leersia oryzoides (L.) Sw., a wild relative of rice (Oryza sativa L.), can produce auxins, solubilize phosphate, have antifungal activities and increase root and shoot growth of rice and Bermuda grass (Cynodon dactylon (L.) Pers.) seedlings. Since these endophytes are located within roots and root hairs, their exploitation may be utilized to increase crop production. Martins et al. (2018) further show that diazotrophs like strains of some strains of Azospirillum and Herbaspirillum spp. can improve nitrogen efficiency in maize and boost grain yields. Zhou et al. (2018) also show that the leaf endophyte Phialemonium inflatum can be applied to seeds and seedlings of cotton to protect seedlings against root-knot nematode infection. Finally, Vignale et al. (2018), studying the seed-borne fungus Epichloë show that plants colonized by these endophytes can affect the extramatrical development of two arbuscular mycorrhizae, Rhizophagus intraradices and Gigaspora rosea, by promoting their colonization, demonstrating that some seed-borne fungi can also affect some below ground colonizers. 


\section{Conclusions and future prospects}

Despite many decades of little interest and research attention, the microbiota of seeds is now developing into a major focus area for the exploration and understanding of plant microbiomes and beneficial plantmicrobial interactions. Seeds, like no other plant organ, provide insights into the origin of plant microbiota, but also how the interactions of seed-associated microbes may be utilized to improve plant growth. This Special Issue focusing on soil, seeds, plant and microorganisms has highlighted important advances in understanding the complex plant-seed-soil-microbe interface. While important foundational data on microbial taxa, their putative functions and interactions with other plant parts and the soil are discussed. This Special Issue also points the way for additional studies to gain a more comprehensive knowledge and understanding of the ecology of seed microbiota. Presently, our knowledge of the ecology of seed microbiota lacks far behind our understanding of the rhizosphere and phyllosphere microbiota. And while the work highlighted in this Special Issue represents only the beginning of what may be a fruitful path forward in understanding the origin of seed microbiota, the routes and modes of seed colonizing, the sites of establishment within seeds, and the function of these microbes in plant and soil habitats, we can expect great advances in coming years.

Many questions remain. For example, what factors determine efficient seed colonization by microorganisms and the successful establishment of populations in and on seeds? As with the rhizosphere and phyllosphere, does the plant physiotype shape the composition of microbial seed assemblages? Are seed microbiota different between plant families? What are the factors that allow microbes to persist in dormant seeds? What are the functional traits necessary for microbes to be able to invade and establish in plant seeds? Very often dormancy in seeds is concomitant with extreme drying begging the question of whether microbes require some level of desiccation tolerance to survive during seed dormancy. Some pioneer studies are indeed pointing to the capacity of some microorganisms to cope with stress conditions likely accompanying the seed maturation process as an essential component of efficient seed colonization (Pochon et al. 2012, 2013). What role do seed microbiota play in the assembly of the plant microbiota? Because the seed microbiota represent the initial microbial colonizers of emerging seedlings before they recruits microbes from the surrounding environment (rhizosphere or phyllosphere), the seed microbiota might play important roles in the assembly and function of the plant microbiome. While these and many other questions remain to be answered, the research highlighted in this Special Issue suggests that the future is bright for this emerging and productive area of inquiry.

Acknowledgements All the contributors of this Special Issue, the anonymous reviewers for their excellent works, the Editor-inchief Hans Lambers and the managing editor Lieve Bultynck, Philippe Hinsinger for editing the Marschner Review and all the staff from Plant and Soil to let us the opportunity to make this thematic volume are gratefully acknowledged. This Special Issue has helped us to show advances in seed, soil, plants and microorganisms research and we are grateful to them.

\section{References}

Adam E, Bernhart M, Müller H, Winkler J, Berg G (2018) The Cucurbita pepo seed microbiome: genotype-specific composition and implications for breeding. Plant Soil. https://doi.org/10.1007/s11104-016-3113-9

Alibrandi P, Cardinale M, Rahman MM, Strati F, Ciná P, de Viana ML, Giamminola EM, Gallo G, Schnell S, de Filippo C, Ciaccio M, Puglia AM (2018) The seed endosphere of Anadenanthera colubrina is inhabited by a complex microbiota, including Methylobacterium spp. and Staphylococcus spp. with potential plant-growth promoting activities. Plant Soil 1-19. https://doi.org/10.1007/s11104-017-3182-4

Barret M, Guimbaud JF, Darrasse A, Jacques MA (2016) Plant microbiota affects seed transmission of phytopathogenic micro-organisms. Mol Plant Pathol 17(6):791-795. https://doi.org/10.1111/mpp.12382

Brader G, Compant S, Vescio K, Mitter B, Trognitz F, Ma L-J, Sessitsch A (2017) Ecology and genomic insights of plantpathogenic and -nonpathogenic endophytes. Annu Rev Phytopathol 55:61-83

Chen T, Nan Z, Zhang X, Hou F, Christensen M, Baskin C (2018) Does dormancy protect seeds against attack by the pathogenic fungus Fusarium tricinctum in a semiarid grassland of Northwest China? Plant Soil. https://doi.org/10.1007 /s11104-017-3420-9

Compant S, Clément C, Sessitsch A (2010) Plant growthpromoting bacteria in the rhizo- and endosphere of plants. Their role, colonization, mechanisms involved and prospects for utilization. Soil Biol Biochem 42:669-678

Compant S, Saikkonen K, Mitter B, Campisano A, MercadoBlanco J (2016) Editorial special issue: soil, plants and endophytes. Plant Soil 405(1):1-11

Darrasse A, Barret M, Cesbron S, Compant S, Jacques MA (2018) Niches and routes of transmission of Xanthomonas citri pv. fuscans to bean seeds. Plant Soil. https://doi.org/10.1007 /s11104-017-3329-3 
Escobar Rodríguez C, Mitter B, Barret M, Sessitsch A, Compant S (2018) Commentary: seed bacterial inhabitants and their routes of colonization. Plant Soil. https://doi.org/10.1007 /s11104-017-3368-9

Glassner H, Zchori-Fein E, Yaron S, Sessitsch A, Sauer U, Compant S (2018) Bacterial niches inside seeds of Cucumis melo L. Plant Soil. https://doi.org/10.1007/s11104-017-3175-3

Hardoim PR, van Overbeek LS, Berg G, Pirtillä AM, Compant S, Campisano A, Döring M, Sessitsch A (2015) The hidden world within plants: ecological and evolutionary considerations for defining functioning of microbial endophytes. Microbiol Mol Biol Rev 79(3):293-320

Jack ALH, Nelson EB (2018) A seed-recruited microbiome protects developing seedlings from disease by altering homing responses of Pythium aphanidermatum zoospores. Plant Soil. https://oi.org/10.1007/s11104-017-3257-2

Kauppinen M, Saikkonen K, Helander M, Pirttilä AM, Wäli PR (2016) Epichloë grass endophytes in sustainable agriculture. Nat Plants 2:15224. https://doi.org/10.1038 /nplants.2015.224

Li X-Z, Song M-L, Yao X, Chai Q, Li C-J, Nan Z-B, Simpson WR (2017) The effect of seed-borne fungi and Epichloë endophyte on seed germination and biomass of Elymus sibiricus. Front Microbiol 8:2488. https://doi.org/10.3389/fmicb.2017.02488

Martins MR, Jantalia CP, Reis VM, Döwich I, Polidoro JC, Alves BJR, Boddey RM, Urquiaga S (2018) Impact of plant growth-promoting bacteria on grain yield, protein content, and urea- ${ }^{15} \mathrm{~N}$ recovery by maize in a Cerrado Oxisol. Plant Soil. https://doi.org/10.1007/s11104-017-3193-1

Maude RB (1996) Seedborne diseases and their control: principles and practice. $\mathrm{CAB}$ International, Wallingford

Mercado-Blanco J (2015) Life of microbes inside the plant. In: Lugtenberg BJJ (ed) Principles of plant-microbe interactions. Springer International Publishing, Berlin, pp 25-32. https://doi.org/10.1007/978-3-319-08575-3 5

Mercado-Blanco J, Lugtenberg BJJ (2014) Biotechnological applications of bacterial endophytes. Curr Biotechnol 3:60-75

Nelson EB (2018) The seed microbiome: origins, interactions, and impacts. Plant Soil. https://doi.org/10.1007 /s11104-017-3289-7

Pitzschke A (2018) Molecular dynamics in germinating, endophyte-colonized quinoa seeds. Plant Soil. https://doi. org/10.1007/s11104-017-3184-2

Pochon S, Terrasson E, Guillemette T, Iacomi-Vasilescu B, Georgeault S, Juchaux M, Berruyer R, Debeaujon I, Simoneau P, Campion C (2012) The Arabidopsis thalianaAlternaria brassicicola pathosystem: a model interaction for investigating seed transmission of necrotrophic fungi. Plant Methods 8:16

Pochon S, Simoneau P, Pigné S, Balidas S, Bataille-Simoneau N, Campion C, Jaspard E, Calmes B, Hamon B, Berruyer R, Juchaux M, Guillemette T (2013) Dehydrin-like proteins in the necrotrophic fungus Alternaria brassicicola have a role in plant pathogenesis and stress response. PLoS One 8:e75143
Rezki S, Campion C, Simoneau P, Jacques M-A, Shade A, Barret M (2018) Assembly of seed-associated microbial communities within and across successive plant generations. Plant Soil. https://doi.org/10.1007/s11104-017-3451-2

Saikkonen K, Faeth SH, Helander M, Sullivan TJ (1998) Fungal endophytes: a continuum of interactions with host plants. Annu Rev Ecol Syst 29:319-343. https://doi.org/10.1146 /annurev.ecolsys.29.1.319

Saikkonen K, Young CA, Helander M, Schardl CL (2016) Endophytic Epichloë species and their grass hosts: from evolution to applications. Plant Mol Biol 90:665-675. https://doi.org/10.1007/s11103-015-0399-6

Sánchez-López AS, Thijs S, Beckers B, González-Chávez MC, Weyens N, Carrillo-González R, Vangronsveld J (2018) Community structure and diversity of endophytic bacteria in seeds of three consecutive generations of Crotalaria pumila growing on metal mine residues. Plant Soil. https://doi.org/10.1007/s11104-017-3176-2

Shearin ZRC, Filipek M, Desai R, Bickford WA, Kowalski KP, Clay K (2018) Fungal endophytes from seeds of invasive, non-native Phragmites australis and their potential role in germination and seedling growth. Plant Soil. https://doi. org/10.1007/s11104-017-3241-X

Truyens S, Weyens N, Cuypers A, Vangronsveld J (2015) Bacterial seed endophytes: genera, vertical transmission and interaction with plants. Environ Microbiol Rep 7:40-50. https://doi.org/10.1111/1758-2229.12181

Vacher C, Hampe A, Porté AJ, Sauer U, Compant S, Morris CE (2016) The phyllosphere: microbial jungle at the plantclimate interface. Annu Rev Ecol Evol Syst 47:1-24

Verma SK, Kingsley K, Bergen M, English C, Elmore M, Kharwar RN, White JF (2018) Bacterial endophytes from rice cut grass (Leersia oryzoides L.) increase growth, promote root gravitropic response, stimulate root hair formation, and protect rice seedlings from disease. Plant Soil. https://doi. org/10.1007/s11104-017-3339-1

Vignale MV, Iannone LJ, Scervino JM, Novas MV (2018) Epichloë exudates promote in vitro and in vivo arbuscular mycorrhizal fungi development and plant growth. Plant Soil. https://doi.org/10.1007/s11104-017-3173-5

White JF, Kingsley KI, Kowalski KP, Irizarry I, Micci A, Soares MA, Bergen MS (2018) Disease protection and allelopathic interactions of seed-transmitted endophytic pseudomonads of invasive reed grass (Phragmites australis). Plant Soil. https://doi.org/10.1007/s11104-016-3169-6

Zhang M, Xu J, Liu G, Yao X, Ren R, Yang X (2018) Proteomic analysis of responsive root proteins of Fusarium oxysporuminfected watermelon seedlings. Plant Soil. https://doi. org/10.1007/s11104-017-3294-X

Zhou W, Wheeler TA, Starr JL, Valencia CU, Sword GA (2018) A fungal endophyte defensive symbiosis affects plantnematode interactions in cotton. Plant Soil. https://doi. org/10.1007/s11104-016-3147-z 